\title{
Effect of soluble fiber or fructooligosaccharide supplementation upon trinitrobenzenesulphonic acid induced colitis in rats ${ }^{1}$
}

\author{
Efeito da suplementação de fibra solúvel ou frutooligossacarídeo na colite induzida \\ por ácido trinitrobenzenossulfônico em ratos
}

\author{
Sthela Maria Murad-Regadas², Marcellus Henrique Loiola Ponte de Souza ${ }^{3}$, Gerly Anne de Castro Brito ${ }^{4}$, Lusmar Veras \\ Rodrigues $^{5}$, Francisco Sérgio Pinheiro Regadas ${ }^{6}$, Paulo Roberto Leitão de Vasconcelos ${ }^{7}$
}

1. Research performed at Department of Surgery, Faculty of Medicine, Federal University of Ceará (UFC), Brazil.

2. PhD, Head of Anorectal Physiology Unit. Clinic Hospital. Faculty of Medicine, UFC, Brazil.

3. Assistant Professor, Department of Physiology and Pharmacology, Faculty of Medicine, UFC, Brazil.

4. Assistant Professor, Department of Morphology, UFC, Brazil.

5. Associate Professor, Head of Department of Surgery, UFC, Brazil.

6. Full Professor, Department of Digestive Surgery, UFC, Brazil.

7. PhD, Coordinator of Post-Graduation Program, UFC, Brazil.

\begin{abstract}
Purpose: To evaluate the effect of soluble fiber or fructooligosaccharide (FOS) supplementation upon trinitrobenzene sulphonic acid (TNBS)-induced colitis in rats. Methods: 64 Wistar rats were given water, soluble fiber or FOS intragastrically during 14 days prior to colitis induction with TNBS $(n=48)$ or rectal enema with water ( $n=16$; control group). On the 7th or 14th day following colitis induction the rats were weighed and euthanized in order to determine the colon weight/length ratio and macroscopic and microscopic scores. Results: On the 7th day following colitis induction the body weight had decreased significantly, the colon weight/length ratio had increased and macroscopic and microscopic colon lesions were observed. On the 14th day following colitis induction no difference in body weight was observed, in spite of the persistence of macroscopic and microscopic lesions and increased colon weight/length ratio. Supplementation with soluble fiber or FOS did not revert colon lesions or any of the study parameters. Supplementation with FOS, but not with fiber, was associated with increased colon weight/length ratio on the 14th day. Conclusion: Supplementation with soluble fiber or FOS produced no significant impact on TNBS-induced colitis in rats.
\end{abstract}

Key words: Colitis. Dietary Fiber. Trinitrobenzenesulphonic Acid. Rats.

\section{RESUMO}

Objetivo: Avaliar a suplementação de fibra solúvel ou frutooligossacarídeos (FOS) na colite induzida por TNBS em ratos. Métodos: Sessenta e quatro ratos Wistar receberam por gavagem água, fibra solúvel ou FOS. Após 14 dias, foram submetidos à indução de colite com TNBS. O grupo controle recebeu água por gavagem e por enema retal. Decorridos 7 ou 14 dias, após a avaliação do peso, os ratos foram sacrificados e o peso do colo, escores macroscópicos e microscópicos da lesão cólica foram aferidos. Resultados: No $7^{\circ}$ dia após indução da colite, houve uma significativa diminuição do peso dos ratos, um aumento do peso do cólon e lesão cólica macroscópica/microscópica. A suplementação com fibra ou FOS não reverteu nenhum destes parâmetros. No $14^{\circ}$ dia após a indução da colite não foram observadas diferenças no peso dos ratos, entretanto houve uma persistência da lesão cólica macroscópica/microscópica e do aumento do peso do cólon. A suplementação com fibra ou FOS não reverteu à lesão cólica. A suplementação de FOS, mas não de fibra, aumentou o peso do colo comparado com o grupo colite no $14^{\circ}$ dia. Conclusão: A suplementação com fibra solúvel ou com FOS não alterou a colite por TNBS em ratos.

Descritores: Colite. Fibra na Dieta. Ácido Trinitrobenzenossulfônico. Ratos.

\section{Introduction}

Crohn's disease (CD) and ulcerative colitis (UC) are among the most common intestinal inflammatory diseases (IBD). Characterized by chronic inflammation of the intestine, their etiology remains unclear. No completely effective therapy is so far available for patients with IBD, but a number of experimental models have been tested in order to develop one. One of the most commonly used is a model with colitis induced by trinitrobenzene sulphonic acid (TNBS). ${ }^{1}$ Fermentable fibers play an important role in the maintenance of normal colon cell function. They are metabolized by intestinal bacteria producing short-chain fatty acids. Of these, butyrate provides approximately 75\% of the oxigen required by the colonocytes. ${ }^{2}$ Butyrate is involved in other important processes, such as colonocyte homeostasis, hydroelectrolithic exchange, mucus production, ion and bicarbonate absorption and trophism 
of the intestinal epithelium, thereby stimulating proliferation in the colon. Likewise, non-digestible polysaccharides in the large intestine, such as fructooligosaccharide (FOS) ${ }^{-}$a prebiotic soluble fiber ${ }^{-}$are metabolized and used as a substrate for bifidobacteria and lactobacilli, which produce short-chain fatty acids during fermentation. ${ }^{3}$ Some studies indicate that a reduction of short-chain fatty acids in the colon can damage the mucosal membrane, as in colitis when the membrane is no longer protected by fatty acids because a segment of the intestine has become inactive. These changes have been reverted by intraluminal application of fatty acids. ${ }^{4}$ Likewise, fatty acids or butyrate enemas administered to patients with UC and to experimental models with IBD increased the concentration of these substances in the intestinal lumen, repairing inflammatory damage. However, other studies have failed to reproduce these results. ${ }^{5,6}$ Oral supplementation with fiber or prebiotics has therefore been administered as an alternative to enema. Different types of fiber have been evaluated with varying results, such as fiber from the seeds of plantago ovata, ${ }^{7}$ pectin, ${ }^{8}$ resistant starch ${ }^{9}$ and prebiotics (inulin ${ }^{10}$ and FOS $^{11}$ ). Thus, the Purpose of the present study was to evaluate the effect of prebiotic (FOS) or soluble fiber supplementation upon TNBS-induced colitis in rats.

\section{Methods}

\section{Experimental design}

The study employed 64 male Wistar rats weighing $300 \mathrm{~g}$ on the average. The animals were kept at the laboratory of experimental surgery at the medical school of Universidade Federal do Ceará under adequate humidity and temperature conditions with access to water and food ad libitum in accordance with the guidelines of the US Department of Health and Human Services (1985). Using TNBS, colitis was induced in 48 rats (Colitis Group) distributed at random in three subgroups of 16 animals each, according to the substance of intragastric infusion: Water (Subgroup 1), soluble fiber/guar gum (Subgroup 2 ), and fructooligosaccharides (Subgroup 3). The animals were evaluated on the seventh $(n=8)$ or 14 th $(n=8)$ day following induction. A control group (non-Colitis Group) of 16 animals were submitted to rectal enema with water and evaluated on the seventh $(n=8)$ or 14 th $(n=8)$ day following transrectal infusion. The rats in this group were not supplemented with fiber.

\section{Intragastric infusion}

Each day the animals in the Colitis Group (CG) were given two intragastric infusions of water ( $3 \mathrm{ml}$, twice daily), soluble fiber (1g in $3 \mathrm{ml}$, twice daily) or FOS (1g in $3 \mathrm{ml}$, twice daily) with a four-hour interval. This amount of fiber/FOS corresponds to $5 \%$ of the animal's daily food consumption. The animals were allowed to consume water and feed ad libitum during this period. The procedure was initiated 14 days before colitis induction and continued until the animals were sacrificed on the seventh or 14th day following induction, corresponding to a total infusion period of 21 or 28 days. An 11-cm long type 6 Fr catheter was introduced orogastrically though a mouthpiece designed to keep the animal's mouth open during the procedure.

\section{Colitis induction/transrectal water infusion}

Colitis induction was carried out 14 days after initiating intragastric infusion with fiber or FOS. During the 12 hours preceding the procedure the animals were given only water. One hour prior to the procedure the colon was submitted to an enema with $20 \mathrm{ml}$ saline through a 6 Fr rectal probe inserted up to $8 \mathrm{~cm}$ from the anal margin. The animals were then isolated and anesthetized with diethyl ether fumes following which a $4 \mathrm{Fr}$ polyethylene catheter was inserted rectally up to $8 \mathrm{~cm}$ from the anal margin. $20 \mathrm{mg}$ TNBS (SigmaAldrich-Brasil) diluted in a 50\% ethanol solution was then applied at a total volume of $0.8 \mathrm{ml}$ per animal. ${ }^{11}$ The animals were kept suspended by the tail for 30 seconds to prevent the solution from flowing back. The animals in the control group were submitted to a $0.8 \mathrm{ml}$ transrectal water infusion.

\section{Surgical procedure}

The anesthetized animals were placed in dorsal decubitus on a wooden board with all four limbs immobilized and then submitted to laparotomy by xypho-pubic median incision and exposure of the abdominal cavity, exposing the rectum and descending colon $6 \mathrm{~cm}$ from the pubic symphysis. The fragments were sectioned for determination of inflammatory parameters. The animals were subsequently euthanized by cervical dislocation.

\section{Weight evolution}

All the animals were weighed by the same researcher at baseline and on both evaluation days (7th and 14th following colitis induction).

\section{Colon weight/length ratio}

The sectioned colorectal segments were weighed and measured in order to calculate the respective colon weight (mg)/length $(\mathrm{cm})$ ratios. $^{12}$

\section{Macroscopic evaluation}

The colorectal segments were evaluated by two researchers blinded to group assignments by applying the inflammation score (0-10) described by Morris et al. ${ }^{1}$

(0) Normal appearance

(1) Focal hyperhemia, but no ulcer

(2) Ulceration without hyperhemia or bowel wall thickening

(3) Ulceration with inflammation at one site

(4) Ulceration / inflammation in two or more sites

(5) Main lesion extending for $1 \mathrm{~cm}$ along the colon

(6-10) When the main lesion extends for more than $2 \mathrm{~cm}$ along the colon, one score is added for each additional centimeter. 


\section{Microscopic evaluation}

The excised colorectal segments were submitted to routine histological sectioning and staining with hematoxilin and eosin. The slides were given microscopy scores (0-11), according to the following criteria. ${ }^{13}$

- Loss of mucosal architecture (0-3)

- Cellular infiltration (0-3)

- Muscle thickening (0-3)

- Crypt abscess in formation (0-1)

- Globet cell depletion (0-1)

\section{Statistical analysis}

The results were subjected to variance analysis as expounded by Kruskal-Wallis. The Purpose of the analysis was to compare the three groups (water, soluble fiber and FOS) on the 7th and 14th day following colitis induction (evaluation days of the study). When a significant difference was found, the analysis was complemented with Wilcoxon's test. In all tests the level of statistical significance was set at 0.05 . Significant values are marked with an asterisk.

\section{Results}

On the seventh day following colitis induction with TNBS the animals in the Colitis Group weighed significantly less than those of the non-Colitis Group (nCG) (Figure 1). However, no difference was observed between the groups supplemented with water, fiber and FOS (Panel A). On the fourteenth day following colitis induction (Panel B) no body weight difference was observed between the Colitis Group and the non-Colitis Group. The administration with TNBS produced a considerable macroscopic colonic lesion, as observed on both evaluation days (Figures 2 and 3). No difference was observed with regard to the two evaluation days between the groups supplemented with water, fiber and FOS. Likewise, on both evaluation days colonic lesions caused by administration with TNBS could be seen microscopically in animals from the Colitis Group, but not among the controls (nCG) (Figures 4 and 5). However, no difference was observed between the groups supplemented with water, fiber and FOS with regard to the two evaluation days. It's demonstrated an increase in the colon weight/length ratio after TNBS administration on both evaluation days, compared to the control group (Figure 6). On the 14th day the colon weight/length ratio had increased for animals supplemented with FOS but not with soluble fiber, as compared animals in the Colitis Group (Panel B).
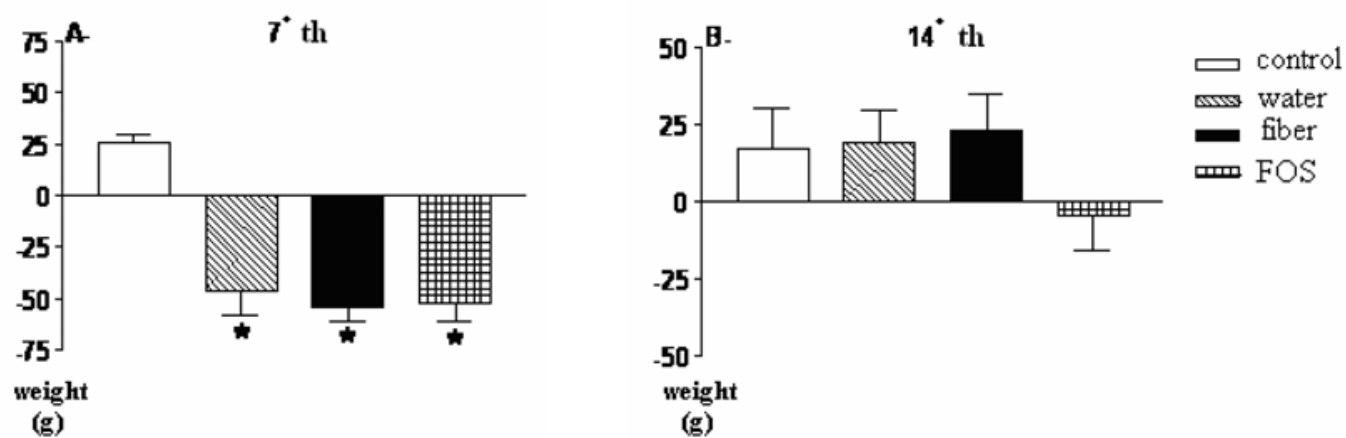

FIGURE 1 - Effect of soluble fiber or fructooligosaccharide (FOS) supplementation upon the body weight of rats with colitis induced by transrectal administration of trinitrobenzene sulphonic acid (TNBS) dissolved in ethanol. The animals were weighed 7 days (Panel A) or 14 days (Panel B) following induction. The results are expressed as average values \pm MSE per group eight animals. $\left(^{*}\right) p<0.05$ compared to the control group. Kruskal Wallis test.
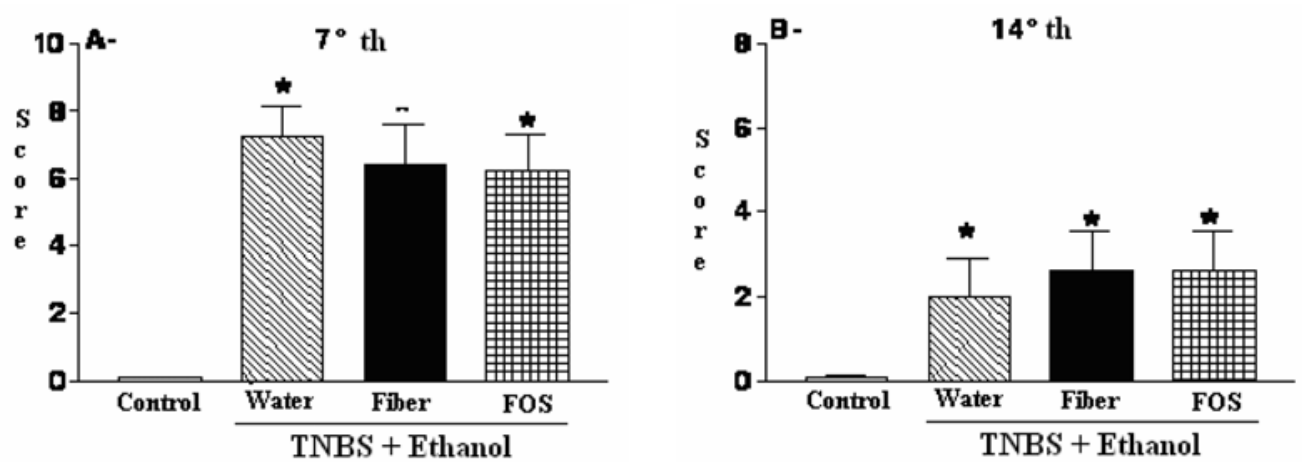

FIGURE 2 - Macroscopic colon lesions induced in rats by transrectal administration of trinitrobenzene sulphonic acid (TNBS) dissolved in ethanol were not inhibited by supplementation with soluble fiber or fructooligosaccharide (FOS). Colon lesions were evaluated on the 7th day (Panel A) or the 14th day (Panel B). The results are expressed as average values \pm MSE per group eight animals.. $\left(^{*}\right) p<0.05$ compared to the control group. Kruskal Wallis test. 

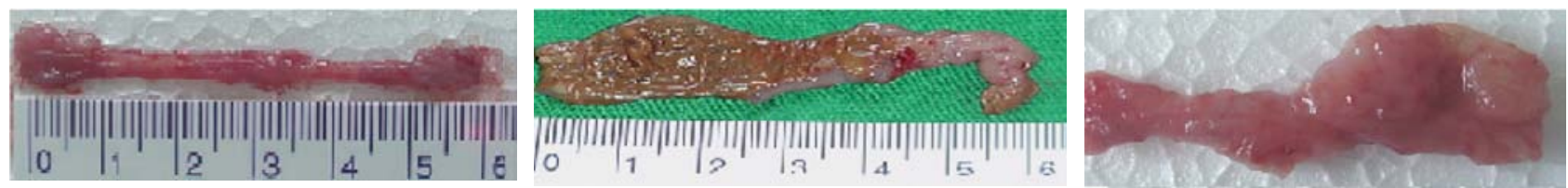

FIGURE 3 - Macroscopic Evaluation - longitudinal sections of colorectal segment.

a- Normal appearance (non-Colitis Group)

b- Main lesion extends for more than $4 \mathrm{~cm}$ along the colon (Colitis Group-day 7)

c- Bowel wall thickening (Colitis Group-day 14)
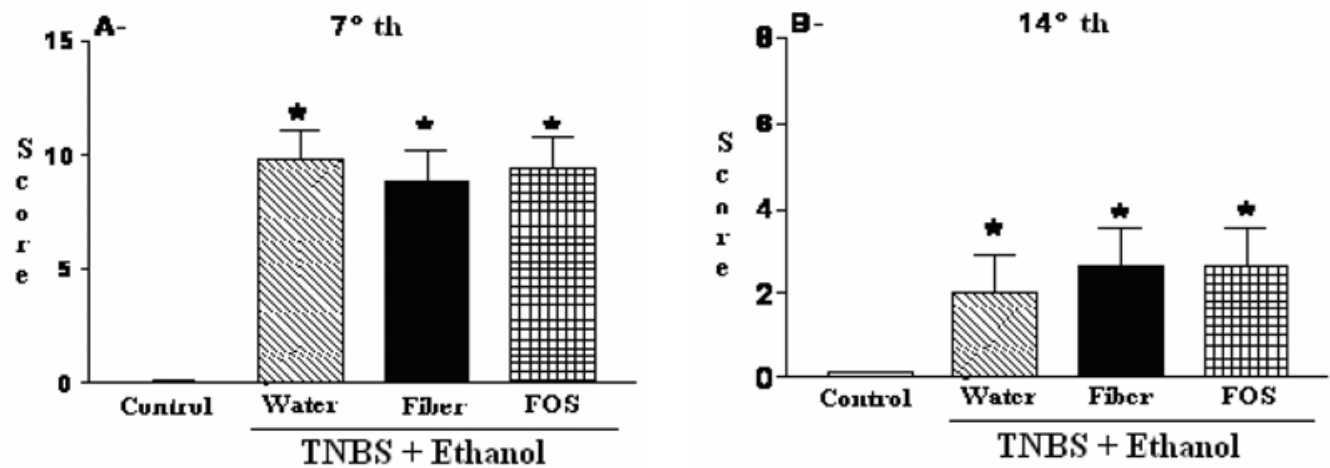

FIGURE 4 - Macroscopic colon lesions induced in rats by transrectal administration of trinitrobenzene sulphonic acid (TNBS) dissolved in ethanol were not inhibited by supplementation with soluble fiber or fructooligosaccharide (FOS). Colon lesions were evaluated on the 7th day (Panel A) or the 14th day (Panel B).. The results are expressed as average values \pm MSE per group eight animals. (*) $p<0.05$ compared to the control group. Kruskal Wallis test.
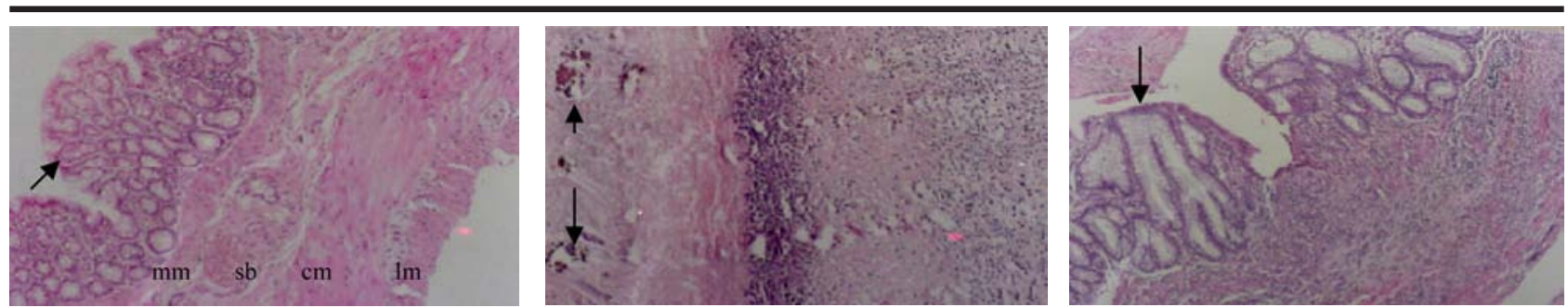

FIGURE 5 - Microscopic Evaluation - Photomicrograph showing longitudinal sections of colorectal segment.

a - Mucosal membrane with intact Lieberkühn crypts (arrow) and abundant globet cells. mucosal muscle (mm); submucosal (sb), circular muscle (cm), longitudinal muscle (lm). HE 40X. (non-Colitis Group)

b - The inflammatory process progressed with loss of the mucosal architecture, decrease of globet cells, necrose (arrow) and increase of inflammatory cell infiltration along the entire colon wall by the 7th day following induction with TNBS. HE 100X.

c - The mucosal architecture had partly recovered on the 14th day following induction with TNBS (arrow). Lesions were still visible with colon wall thickening and cell infiltrate. HE 100X.
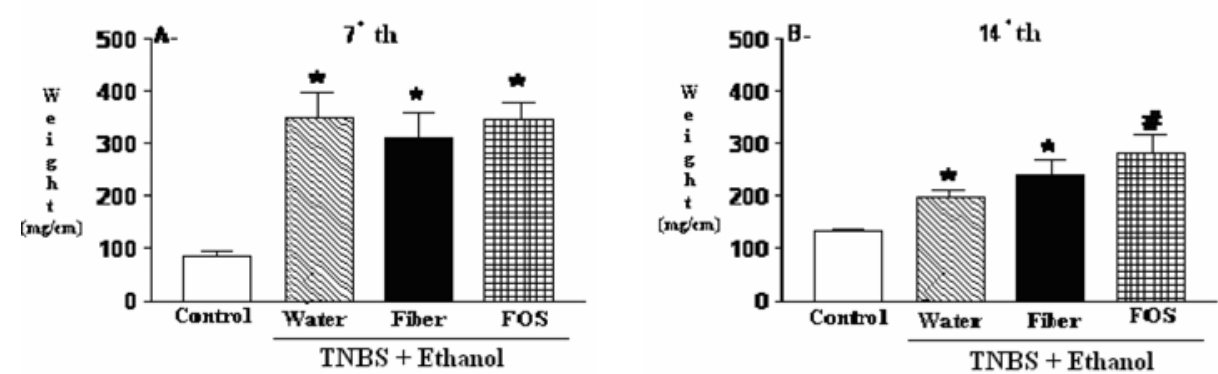

FIGURE 6 - Effect of soluble fiber or fructooligosaccharide (FOS) supplementation upon the colon weight of rats with colitis induced by transrectal administration of trinitrobenzene sulphonic acid (TNBS) dissolved in ethanol. The colon weight/length ratio was determined on the 7th day (Panel A) or the 14th day (Panel B). The results are expressed as average values \pm MSE per group eight animals. $\left(^{*}\right) p<0.05$ compared to the control group. Kruskal Wallis test. 


\section{Discussion}

Fermentable fibers possess a range of properties beneficial to the organism and have been widely used not only as regular dietary components, but also as an aid in the treatment of certain pathologies. ${ }^{14,15}$ However, the use of fibers and prebiotics in the treatment of inflammatory diseases and in colitis models has been subject to controversy in the literature. Nevertheless, although reported studies have applied different methods and used different samples and parameters, there is considerable evidence that supplementation with fibers and prebiotics produces beneficial effects on inflammatory disease and in colitis models. ${ }^{7,9,10,11}$

In the Colitis Group, no significant difference in body weight gain was observed among the three subgroups (water, fiber and FOS). However, on the 14th day following colitis induction the colon weight/length ratio of the animals in the FOS subgroup was significantly higher than that of the two other subgroups. The macroscopic and microscopic scores of the three subgroups presented no statistically significant diffeence on either evaluation day. When testing the effect of fibers from Plantago ovata seeds upon TNBS-induced colitis, Rodriguezcabezas et $\mathrm{al}^{7}$ found lower macroscopic and microscopic scores and lower TNF-a and nitrous oxide dosages on the 7th day following colitis induction, although they used half the dose of TNBS (10 mg) employed in the present study. The latter fact may account for differences between their findings and ours. Cherbut et al ${ }^{11}$ reported significantly reduced macroscopic scores of myeloperoxidase (MPO) activity in a study evaluating FOS supplementation in a model of TNBS-induced colitis. No microscopic evaluation was performed. The macroscopic scores of the present study were different though a similar methodology was employed. The animals tested by Cherbut and colleagues ${ }^{11}$ displayed higher macroscopic scores than our animals on the 14th day following induction (two additional parameters had been incorporated into the score). The macroscopic scores of present study had decreased by the 14th day with no significant difference between the FOS and water subgroups. Moreau et $\mathrm{al}^{9}$ tested three diets (basal, FOS and resistant starch) in a model of colitis induced by dextran sulfate sodium. On the 7th and 14th day following induction, the authors registered the colon weight/length ratio, macroscopic scores, microscopic scores as well as fatty acid concentrations in the cecum and blood. Their findings for fatty acid and butyrate production and for inflammatory response differed among the groups. As shown by the macroscopic and microscopic scores on the 7th and 14th day, the inflammatory response of the group receiving resistant starch was significantly lower than that of the groups treated with FOS and basal diet. The authors suggest the produced substrates may vary in accordance with the fibers used. Compared to the group receiving resistant starch, the FOS group produced smaller amounts of fatty acids in the cecum, a fact which may be accounted for by bacterial growth in the colon under the influence of UC. The results match our own with regard to FOS supplementation although different colitis models were used. Likewise, the colon weight/ length ratio was higher in the FOS group 14 days following colitis induction. In another experiment, Videla et $\mathrm{al}^{10}$ used inulin, a prebiotic consisting of $15-40 \%$ polysaccharide chains. Supplementation was provided intragastrically (400 mg/day) in a model with dextran sulfate sodium-induced colitis. The area of inflammation was reduced (according to microscopic scores), as was the MPO activity and the release of inflammatory mediators (thromboxane B2, leukotriene B4 and prostaglandin E2). In spite of the reduced number of polysaccharide chains, inulin reduced the inflammatory response in animals with dextran sulfate sodium-induced colitis on the fifth day of the experiment. In contrast, the present study employed FOS which consists of 95\% short polysaccharide chains. The more polysaccharide chains in the diet, the more fatty acids are produced in the organism. The present study found a significant difference between the Colitis Group and the non-Colitis Group, but not between the three CG subgroups. The Colitis Group presented significantly increased inflammatory parameters and reduced body weight on the 7th day following colitis induction. However, on the 14th day this difference was no longer observed. Both the colon weight/length ratio and the macroscopic and microscopic scores of the animals in the Colitis Group were higher than in the non-Colitis Group on both evaluation days. The inflammatory process progressed with loss of the mucosal architecture, decrease of globet cells and increase of inflammatory cell infiltration along the entire colon wall on the 7th day following induction. Although the mucosal architecture had partly recovered on the 14th day, lesions were still visible with colon wall thickening and cell infiltrate in the three subgroups. Thus, the colitis model, using $20 \mathrm{mg}$ TNBS of present study, produced findings comparable to those of Yamada et al. ${ }^{12}$

In conclusion, intragastric supplementation with soluble fiber or FOS produced no significant effect upon the inflammatory parameters in the acute and chronic phase following onset of TNBS-induced colitis. The colitis model reproduced the acute and chronic phase of the inflammation.

\section{Conclusion}

Supplementation with soluble fiber or FOS produced no significant impact on TNBS-induced colitis in rats.

\section{References}

1. Morris GP, Beck PL, Herridge W, Depew W, Szewczuk MR, Wallace JL. Hapten induced model of chronic inflammation and ulceration in the rat colon. Gastroenterology. 1989;96:795-803.

2. Rombeau JL, Kripke SA. Metabolic and intestinal effects and short-chain fatty acids. J Parenter Enteral Nutr. 1990;14:181-5. 
3. Le Blay G, Michel C, Blottiere HM, Cherbut C. Prolonged intake of fructo-oligosaccahrides induces a short-term elevation of lactic acid-producing bacteria and a persistent in cecal butyrate in rats. J Nutr. 1999;129:2231-5.

4. Harig JM, Soergel KH, Komorowski RA et al. Treatment of diversion colitis with short chain fatty acid irrigation. N Engl J Med. 1989;320:23-8.

5. Scheppach WA. Are short chain fatty acids effective in the local treatment of ulcerative colitis? Gastroenterology. 1996;110:1010-4.

6. Butzner JD, Parmar R, Bell CJ, Dalal V. Butyrate enema therapy stimulates mucosal repair in experimental colitis in rat. Gut. 1996;38:568-73.

7. Rodrigues-Cabezas ME, Gálvez J, Lorente MD, Concha A, Camuesco D, Azzouz S, Osuna A, Redondo L, Zarzuelo A. Dietary fiber down-regulates colonic tumor necrosis factor and nitric oxide production in trinitrobenzenesulfonic acid-induced colitic rats. J Nutri. 2002;132:3263-71.

8. Andoh A, Bamba T, Sasaki M. Physiological and antiinflamatory roles of dietary fiber and butyrates in intestinal functions. J Parenter Enteral Nutr. 1999;23:70-3.

9. Moreau NM, Martin LJ, Toquet CS, Laboisse CL, Nguyen PG, Siliart BS, Dumon HJ, Champ MMJ. Restoration of the integriyy of rat caeco-colonic mucosa by resistant starch, but not by fructo-oligosaccharides, in dextran sulfate sodium-induced experimental colitis. Br J Nutr. 2003;90:75-85.

10. Videla S, Vilaseca J, Antolín M, García-Lafuente A, Guarner F, Crespo E, Casalots J, Salas A, Malagelada JR. Dietary inulin improves distal colitis induced by dextran sodium sulfate in the rat. Am J Gastroenterol. 2001;96:1486-93.

11. Cherbut C, Catherine M, Lacannu G . The prebiotic characteristic of fructooligosaccrharides are necessary for reduction of TNBS-induced colitis in rats. J Nutr. 2003;133:21-7.

12. Yamada T, Deitch E, Specian RD et al. Mechanisms of acute and chronic intestinal inflammation induced by indomethacin. Inflammation. 1993;17:641-62.

13. Appleyard CB \& Wallace JL. Reactivation of of hapteninduced colitis and its prevention by anti-inflammatory drugs. Am J Physiol. 1995:32:119-25.

14. Abia R, Mãnas E, Goñi I, Saura-Calixto, F. Fibra alimentaria y su relación con enfermedades cardiovasculares. Nutr Clin. 1989;9:155-64.

15. Weinstock RS, Levine RA. The role of dietary fiber in the management of diabetes mellitus. Nutrition. 1997;4:187-93.

\section{Correspondence:}

Sthela Maria Murad-Regadas

Av. Edilson Brasil Soares, 1892

60834-220 Fortaleza - CE Brazil

Phone:(5585)3257-7728

smregadas@hospitalsaocarlos.com.br
Conflict of interest: none

Financial source: Nutrimed

Received: April 11, 2006

Review: May 09, 2006

Accepted: June 13, 2006

\section{How to cite this article:}

Murad-Regadas SM, Souza MHLP, Brito GAC, Rodrigues LV, Regadas FSP, Vasconcelos PRL. Effect of soluble fiber or fructooligosaccharide supplementation upon trinitrobenzenesulphonic acid induced colitis in rats. Acta Cir Bras. [serial on the Internet] 2006 Sept-Oct;21(5). Available from URL: http://www.scielo.br/acb. 